\title{
Control of zoonoses in Britain: past, present, and future
}

\author{
J C BELL, S R PALMER
}

\begin{abstract}
In the past zoonoses that caused serious human illness also caused serious loss of animal production, but there is growing awareness of the public health problems arising from infections that cause little or no such loss. Much can be learnt from the history of the control of bovine tuberculosis and brucellosis. In both cases there was reluctance to accept that animals were the principal cause of infection, and the earliest attempts at control failed because measures were taken only against clinical cases of the disease. The essential features in control of both infections were: official recognition of a problem, willingness of governments to allocate resources, and cooperation between the medical and veterinary professions. Salmonellosis is the most important zoonotic infection in Britain today, though several Orders have reduced the reservoir of infection in food animals.

It is suggested that a national team of doctors should be set up to investigate and control zoonoses, that this team should be answerable to a central agency, and that it should build up close working relationships with the nominated officers of the veterinary profession.
\end{abstract}

\section{Introduction}

The zoonoses that caused serious human illness in Britain in the past also caused serious loss of animal production. The resulting financial loss to farmers was an essential factor in

Ministry of Agriculture, Fisheries, and Food, Epidemiology Unit, Central Veterinary Laboratory, Weybridge, Surrey KT15 3NB

J C BELL, MRCVS, DVSM, divisional veterinary officer

Public Health Laboratory Service, Communicable Disease Surveillance Centre, London NW9 5EQ

S R PALMER, MA, MFCM, consultant epidemiologist

Correspondence to: Dr S R Palmer, PHLS Cardiff, University Hospital of Wales, Heath Park, Cardiff CF4 4XW. procuring the support of parliament, the cooperation of the agriculture industry, and the will of the veterinary profession to control diseases such as glanders, anthrax, bovine tuberculosis, and bovine brucellosis. Today there is growing awareness of public health problems arising from infections that often cause little or no loss of animal production, such as salmonellosis in poultry, ${ }^{1}$ ornithosis in poultry, ${ }^{2}$ campylobacter contamination of milk, ${ }^{3}$ and $Q$ fever infection in sheep. ${ }^{4}$ The medical profession is pressing for such animal diseases to be controlled, ${ }^{5}$ but who should bear the responsibility and the cost? The protection of human health is the province of the medical authorities, while skill in animal husbandry and disease control lies with the Ministry of Agriculture, Fisheries, and Foods. ${ }^{6}$ Clearly a joint approach is indicated.

\section{Historical lessons}

Traditional methods of control may not be applicable to today's problems but a brief review of the history of the control of bovine tuberculosis and bovine brucellosis illustrates factors for success and failure in the control of zoonoses and the importance of veterinarymedical collaboration.

\section{BOVINE TUBERCULOSIS}

In 1882 Robert Koch made the pronouncement: "Bovine tuberculosis is identical with the disease in man and is thus a disease transmissible to man" and focused attention on the danger of consuming unpasteurised milk. Control of the disease received a major set back in 1901, however, when Koch, having accepted the discovery of differences between bovine and human bacilli, suggested that bovine tuberculosis was not an important threat to humans and that he did not deem it advisable to take any measures against it. ${ }^{8}$ The consequences of this claim were described by Van der Hoeden: "Koch's authority was so great that his rash conclusions were accepted by the majority of physicians. The result was that many hygienic measures that had been advocated were gradually neglected and medical men lost interest in veterinary work on the control of bovine tuberculosis."

The establishment of a correct understanding of the transmissibility of bovine tuberculosis to people and the mitigation of the effects of Koch's statement owe much to the efforts of Sir John M'Fadyean. This distinguished veterinarian challenged Koch and 
was instrumental in the setting up of the Royal Commission on Tuberculosis, which reported in 1907: “Cows' milk containing bovine tubercle bacilli is clearly a cause of tuberculosis and fatal tuberculosis in man. Our results clearly point to the necessity of measures more stringent than those at present in force being taken to prevent the sale and consumption of such milk."10 This commission, which included M'Fadyean as a member, was the first medicoveterinary task force and set the precedent for successful joint investigation of zoonoses.

The first attempts to control tuberculosis in cattle were based on the reporting of clinical disease in dairy cattle. A succession of tuberculosis Orders made from 1913 to 1946 required the removal of cattle affected by various forms of clinical tuberculosis. The tuberculosis Orders were intended purely as public health measures and had little effect on the amount of tuberculosis in cattle. In 1922 the Ministry of Health introduced the Milk (Special Designations) Order, which identified milk from tuberculin tested herds but even so, by the mid-1930s little reduction in the amount of infection in milk had been achieved.

The simple measure of pasterisation of milk, which was proved to be effective and safe in $1925,{ }^{11}$ could have saved many thousands of lives if introduced earlier. In 1944, 37 years after the royal commission's first report, Rich wrote: "In the British Isles, human tuberculosis of bovine origin is proportionately more common than in any other civilised country in the world. The well known fact is a sad commentary on human cupidity. The best estimates indicate that at least 2000 children die annually from bovine tuberculosis in Great Britain simply because the powerful dairy interests, through their political connections, have blocked all attempts to introduce legislation requiring the pasteurisation of milk sold to the public. Numerous newspapers, apparently unwilling to antagonise the dairy interests, have even refused to print a paid announcement by the British Medical Association informing the public that raw milk is unsafe."12

Real progress towards eradication of infection from cattle and dairy products was not made until the Agriculture Act of 1937 empowered the Minister of Agriculture and Fisheries to spend money on the eradication of bovine tuberculosis, allowing cash incentives to be provided for voluntary eradication based on tuberculin testing and removal of reactors. In 1950 the number of herds attested under the voluntary scheme was high enough to make the introduction of a compulsory area eradication plan practicable. In 1960 the whole of Great Britain became an attested area-all cattle became subject to compulsory tuberculin testing with removal and slaughter of reactors.

The widespread introduction of pasteurisation of milk for retail sale followed by compulsory eradication measures for tuberculosis in cattle have successfully brought bovine tuberculosis in man and in cattle under control.

\section{BRUCELLOSIS}

As with bovine tuberculosis, the recognition of the zoonotic origin of human brucellosis was largely the result of the setting up of an official commission by the government. In 1904 the Royal Society was asked to appoint a commission on behalf of the army, navy, and the government of Malta to investigate Malta fever. The joint commission did not have its own veterinary specialist, but was helped by a local veterinary officer in Malta. ${ }^{13}$

Goats were found to be the natural reservoir of Brucella melitensis on the island. ${ }^{14}$ The need to take early action to control the infection was seen clearly by Bruce, the chairman of the commission. On hearing the preliminary results of the experiments by Zammit and Horrocks he wrote: "It may be objected that no exact proof exists that the drinking of milk containing Micrococcus melitensis will give rise to the disease in man. When we take, however, into consideration the results of the feeding and inoculation experiments on monkeys, it may be assumed with safety that the disease is propagated in this way, and that no time should be lost in removing such a grave and insidious danger to the public health."14 Swift and effective action to protect the troops followed, although similar measures to protect the indigenous Maltese population took longer. The 1906 order to the forces banning consumption of unboiled goats' milk dramatically reduced the incidence of Malta fever. ${ }^{15}$

In 1918 the relationship between $B$ melitensis and $B$ abortus, which Bang had identified in cattle, was established by Evans and attention was directed to the public health hazards of infected cows' milk. ${ }^{16}$ As with tuberculosis, the earliest official attempts to control brucellosis in cattle failed because controls were applied only to clinically affected cows. Effective control began with voluntary schemes and was achieved by compulsory eradication measures.
In 1951-2 more than $18^{\circ}$ of bulk milk samples contained brucella. In 1960-1 25-30\% of dairy herds in Britain were infected. Vaccines were available from about 1905 and a scheme to encourage vaccination ran from 1944 to 1950 . In 1962 a vaccination scheme was introduced whereby heifer calves of a specified age were vaccinated free of charge. Vaccination reduced the number of abortions but did not prevent the spread of infection from asymptomatic animals. In 1967 voluntary schemes were introduced for testing and removing reactors from individual herds and in 1975 eradication began in those areas with the highest proportion of attested herds. In November 1979 the whole of Great Britain became subject to compulsory eradication measures for brucellosis in cattle. Cattle are the sole reservoir for brucellosis in Britain and there has been a parallel decline in human and bovine infection.

\section{Discussion}

The control of bovine tuberculosis and brucellosis are major success stories when viewed in the long term yet it took over 30 years in each case from proving that animals were the major source of infection to the introduction of adequate control measures. Important factors in the elucidation of the natural history and control of these diseases were: (a) official recognition of a problem, $(b)$ willingness of government to allocate resources; and $(c)$ a joint medicoveterinary approach. Delay in the introduction of effective control measures may be attributed to: (a) attempting to protect human health while failing to control the disease in animals; $(b)$ directing control measures against only clinical cases of animal disease; and (c) reluctance to act on less than $100 \%$ proof that animals were a major reservoir of infection.

\section{PRESENT PROBLEMS}

The most important zoonosis in Britain today is salmonellosis, particularly since transferable multiple drug resistance among enteric bacteria ${ }^{17}$ and the entry of multiply resistant clones of Salmonella typhimurium into the human food chain ${ }^{18}$ have been demonstrated. When a specific food is implicated it is usually meat, often poultry, but attempts are rarely made to trace the farm of origin. The source of infection for the animals or birds, which may be contaminated feed, ${ }^{19}$ is identified even more rarely.

Liaison among the services concerned in the investigation of salmonellosis was given statutory reinforcement by the Zoonoses Order $1975 .{ }^{2021}$ The identification of salmonellae in certain scheduled animals and birds normally used for food must be reported to a veterinary inspector of the Ministry of Agriculture, Fisheries, and Food or the Department of Agriculture and Fisheries for Scotland. The veterinary inspector responsible for receiving this information, investigating outbreaks, and, if appropriate, applying emergency control measures to protect human health is called the nominated officer. He keeps the medical officers for environmental health and chief environmental health officers informed of salmonella infections in food animals in their territories. The Zoonoses Order has led to the creation of an effective surveillance system to help in the epidemiological investigation of outbreaks of animal salmonellosis and human food poisoning and has also increased communication among veterinary, medical, and environmental health services.

In 1982 an important step was taken towards the reduction of the reservoir of salmonella infection in food animals when two new Orders came into effect. The Diseases of Animals (Protein Processing) Order $1981^{22}$ required home produced processed animal protein intended for use in animal feeds to be free of salmonellae, and the Importation of Processed Animal Protein Order $1981^{23}$ introduced a similar requirement for imported material. There are provisions for the sampling and testing of products and penalties for producers or importers who fail to comply.

The animal origin of most salmonella infections in man was established in the early 1940 s. $^{24}$ How long will it take to bring 
about sufficient improvement in animal husbandry, food processing, and kitchen hygiene to effect an appreciable reduction in the incidence of human salmonella food poisoning ?

\section{THE FUTURE}

It is difficult to predict which zoonoses will become important public health problems but it is certain that salmonella and campylobacter infections will remain major causes of morbidity. Ornithosis reached epidemic proportions in Norway in 1980-1 ( $S$ Aasen, unpublished data) and there is no reason to believe that this could not occur in Britain. As with campylobacter, the source of infection is unknown in $80 \%$ of cases of ornithosis. $Q$ fever occurs both sporadically and in often unexplained explosive outbreaks, but risks of exposure are not known so reasonable advice on avoiding the risk of chronic infection cannot be given to patients with heart valve disease. Listeriosis caused a major problem in Cumbria in 1981 (S Hall, personal communication) and may continue to pose new problems. For example, in Canada in 1981 an outbreak of listeriosis resulted from foodborne infection: the vehicle of infection was coleslaw made from fresh raw vegetables which had been contaminated by untreated sheep manure. ${ }^{26}$ A large outbreak of yersiniosis in 1980 in a boys' school in Dorset was attributed to contact with a pig kept on the school farm (C Bartlett, personal communication).

If yersiniosis, $\mathrm{Q}$ fever, ornithosis, or listeriosis become major public health problems in Britain will the present system be able to cope with investigation and control?

\section{FRAMEWORKS FOR MEDICOVETERINARY COOPERATION}

It is clear that veterinarians should play a major part in the surveillance of zoonoses in collaboration with the medical profession. Although it has been said that "the two professions do not always work together as closely as they should" 27 (and this has been borne out by difficulties encountered during field investigation ${ }^{28}$ ), joint investigations have proved possible and successful. ${ }^{29}$ Notwithstanding shortages of money and manpower, "much could be done from existing resources if the will exists to apply a concerted medicoveterinary collaboration."'s

Informal local and central liaison groups provide a framework for future collaboration between the medical and veterinary professions. By 1975 liaison groups were operating in most parts of Scotland. In England and Wales there are at least 14 groups, most of which were started by nominated officers on the implementation of the Zoonoses Order in July 1975. We suggest that the role of nominated officers should be extended to cover all zoonoses. In 1975 a central zoonoses group was created ${ }^{30}$; members comprised the chief veterinary officer, the chief medical officer of the Department of Health and Social Security, and other representatives of the Public Health Laboratory Service, Department of Health and Social Security, and the State Veterinary Service. Its functions so far have been to brief heads of services and to encourage informal discussion over interdisciplinary problems. We suggest that it should take on a more positive role by indicating needs for research and monitoring field investigations and control measures.

In 1967 the Communicable Disease Scotland Unit was established in Glasgow and acts as a coordinating centre for all laboratory diagnosed infection in Scotland. The unit has an attached veterinary officer of the Department of Agriculture and Fisheries for Scotland to coordinate veterinary and medical information. ${ }^{28}$ In England and Wales the Communicable Disease Surveillance Centre, created in $1977,{ }^{31}$ is the focal point for the collection of data from the Public Health Laboratory Service. Throughout Britain data from the Veterinary Investigation Service and nominated officers are collated by the epidemiology unit of the Central Veterinary Laboratory. Veterinary and medical surveillance of zoonoses in England and Wales is a joint function of the epidemiology unit and Communicable Disease Surveillance Centre and this function was formalised in 1979 by the appointment of a divisional veterinary officer based at the epidemiology unit and seconded part time to Communicable Disease Surveillance Centre.

In order to promote effective and efficient investigation and control of zoonoses in the future we suggest that a national team of doctors equivalent to the nominated officers should be designated. They would cover similar territories, have an 'epidemiological approach to disease problems, be mobile and able to respond rapidly to zoonotic incidents. They should also be answerable to a central coordinating and communications agency. Directors of public health laboratories might immediately fulfil this function, alternatively members of a proposed regionally based team of medical epidemiologists ${ }^{3 i}$ would seem ideally situated to build up a close working relationship within the nominated officer network.

\section{References}

${ }^{1}$ Borland ED. Salmonella infection in poultry. Vet Rec 1975;97:406-8.

2 Palmer SR. Psittacosis in man-recent developments in the UK: a review. f $R$ Soc Med $1982 ; 75: 262-7$.

${ }^{3}$ Robinson DA, Jones DM. Milk-borne campylobacter infection. Br Med f $1981 ; 282: 1374-6$.

- Salmon MM, Howells B, Glencross EJG, Evans AD, Palmer SR. Q fever in an urban area. Lancet 1982; ; :1002-4.

B Anonymous. Preventing animal diseases [Editorial]. Br Med F 1976;i:3556.

- Anonymous. Everybody's business [Editorial]. Vet Rec 1979;104:249.

${ }^{7}$ Koch R. Die aetiologie der tuberculose. Klin Wochenschr 1882;19:221-30.

8 Koch R. Address before the second general meeting. Transactions of the British Congress on Tuberculosis 1902;1:23-35.

- Van der Hoeden J. Tuberculosis. In: Van der Hoeden J, ed. Zoonoses. Amsterdam: Elsevier, 1964:9-49.

${ }^{10}$ Royal Commission on Tuberculosis. Second interim report of the Royal Commission appointed to inquire into the relations of human and bovine tuberculosis. (Cmnd 3322). London: HMSO, 1907.

11 Wilson GS. The pasteurisation of milk. London: Edward Arnold, 1942.

12 Rich AR. The pathogenesis of tuberculosis. 2nd ed. Oxford: Blackwell, 1951.

13 Advisory Committee of Royal Society. Report of the commission appointed by the Admiralty, the $W$ ar Office and the Civil Government of Malta for the investigation of Mediterranean fever. Part 4. London: Harrison, 1906.

14 Advisory Committee of Royal Society. Report of the commission appointed by the Admiralty, the War Office and the Civil Government of Malta for the investigation of Mediterranean fever. Part 3. London: Harrison, 1906.

15 Eyre JWH. Meltensis septicaemia. Lancet 1908;i:1677-82.

${ }_{16}$ Dalrymple-Champneys W. Brucella infection and undulant fever in man. London: Oxford Medical Publications, 1960.

${ }^{17}$ Akiba T, Koyama K, Ishiki Y, Kimura S, Fukushima T. On the mechanism of the development of multiple-drug-resistant clones of Shigella. fapanese fournal of Microbiology 1960;4:219-27.

18 Rowe B, Threlfall EJ. Multiple antimicrobial drug resistance in enteric pathogens. F Antimicrob Chemother 1981;7:1-3.

${ }^{10}$ Hobbs BC, Hugh-Jones ME. Epidemiological studies on Salmonella senftenberg. 1. Relations between animal foodstuff, animal and human isolations. F Hyg (London) 1969;67:81-8.

${ }^{20}$ Lowes E. The Zoonoses Order 1975. Vet Rec 1975;97:32-3.

21 Ministry of Agriculture, Fisheries, and Food. Zoonoses Order. London: HMSO, 1975. (SI No 1030.)

${ }^{22}$ Ministry of Agriculture, Fisheries, and Food. Diseases of Animals (Protein Processing) Order. London: HMSO, 1981. (SI No 676.)

${ }^{23}$ Ministry of Agriculture, Fisheries, and Food. Importation of Processed Animal Protein Order. London: HMSO, 1981. (SI No 677.)

${ }^{24} \mathrm{McCoy} \mathrm{JH}$. Trends in salmonella food poisoning in England and Wales, 1941-72. F Hyg (Lond) 1975;74:271-82.

${ }^{25}$ Palmer SR, Young SEJ. Q fever endocarditis in England and Wales, 197581. Lancet 1982 ;ii:1448-9.

${ }^{26}$ Schlech WF III, Lavigne PM, Bortolussi RA et al. Epidemic listeriosisevidence for transmission by food. $N$ Engl f Med 1983;308:203-6.

27 Anonymous. All doctors great and small [Editorial]. $\mathrm{Br} M e d \mathcal{F} 1978 ; \mathrm{i}: 464$.

28 Sharp JCM. Medical-veterinary liaison in Scotland. Vet Rec 1977;101: 200-1.

${ }^{29}$ Payne DJH, Scudamore JM. Outbreaks of salmonella food-poisoning over a period of eight years from a common source. Lancet 1977; i:124951.

30 Payne DJH, Lowes E. Preventing animal diseases. Br Med 7 1976;i:521

${ }^{31}$ Galbraith NS, Young SEJ. Communicable disease control: the development of a laboratory associated national epidemiological service in England and Wales. Community Med 1980;2:135-43.

(Accepted 18 May 1983) 